\title{
Menopausal hormone therapy and venous thromboembolism
}

\author{
Małgorzata Bińkowska \\ First Department of Obstetrics and Gynecology, Centre of Postgraduate Medical Education, Warsaw, Poland
}

\begin{abstract}
Menopausal hormone therapy (MHT) is the most effective method of treating vasomotor symptoms and other climacteric symptoms related to estrogen deficiency in peri- and postmenopausal period. In addition to estrogen replacement, women with preserved uterus require the addition of progestagen in order to ensure endometrial safety.

One of rare but severe complications of MHT is venous thromboembolism (VTE). The incidence of VTE rises in parallel to women's age and body weight. The condition is also linked to hereditary and acquired risk factors.

Oral estrogens increase the risk of venous thromboembolic complications to varying extents, probably depending on their type and dose used. Observational studies have not found an association between an increased risk of VTE and transdermal estrogen treatment regardless of women's age and body mass index (BMI). Micronized progesterone and pregnanes, including dydrogesterone, have no effect on the risk of VTE, whereas norpregnane progestagens cause an additional increase in risk.

Among hormonal preparations which are commercially available in Poland, the combination of transdermal estradiol with oral dydrogesterone appears to be the optimum choice, as it does not elevate the risk of VTE (compared to patients not using MHT), and dydrogesterone seems to be the progestagen of choice.
\end{abstract}

Key words: menopausal hormone therapy, venous thromboembolism, estrogens, progestagens.

The goals of menopausal hormone therapy (MHT) are to improve the quality of life and to prevent harmful health consequences of chronic estrogen deficiency in perimenopausal and postmenopausal women. The main indications for MHT are menopausal symptoms, primarily moderate and severe vasomotor symptoms (hot flushes, excessive sweating). Other clear indications include premature (onset before the age of 40) and early (onset between the ages of 40 and 45) menopause, prevention and treatment of osteoporosis, especially before the age of 60 , and symptoms of urogenital atrophy [1].

Following the publication of preliminary results of the Women's Health Initiative (WHI) study in 2002, a large number of medical practitioners stopped prescribing MHT to their patients, and many women discontinued the treatment. The decade that followed, however, saw the publication of successive detailed reviews and analyses of the $\mathrm{WHI}$ study, focusing on different age groups and time from the menopause to the onset of therapy. Accordingly, a number of conclusions formulated in 2002-2004 were revised. For example, similarly to many earlier published results of observational studies, it was demonstrated that MHT initiated in women aged 50-59 years and less than 10 years after the menopause reduced the risk of ischemic heart disease, Alzheimer's disease, Parkinson's disease and osteoporotic fractures of the spine and femoral neck.
This group of women also shows a $30 \%$ reduction in overall mortality [2].

Knowledge acquired in recent years on the basis of reanalysis of data collected in WHI studies, other randomized controlled studies, observational studies, outcomes of animal studies and basic research makes it possible to analyze benefits and risks of MHT in relation to multiple different factors. The most important factors include the woman's age, time from the menopause to the initiation of therapy, general state of health, personal and family history of lifestyle diseases, obstetric history, body weight, smoking and alcohol intake. Other major factors are the type of estrogen and progestagen used, their doses and route of administration.

One of rare but the most severe complications potentially occurring during MHT is venous thromboembolism (VTE). The condition involves the formation of a blood clot in the deep vein system, typically in the lower limbs and pelvis, and the risk of life-threatening pulmonary embolism. The incidence of VTE in the population of women aged about 50 years is estimated at 1-2 cases per 10,000 women per year [3].

The correlation between treatment with synthetic estrogens and increased risk of VTE was first described 50 years ago, during studies of the combined contraceptive pill which was being popularized at the time [4]. A gradual tapering of the dose of ethinyloestradiol, 
initially to $50 \mu \mathrm{g}$ and then to $20-35 \mu \mathrm{g}$, was found to have decreased the incidence of the complication. Over the past dozen years or so, attention has turned to the importance of the type of progestagene combined with estrogen. Cyproterone acetate has been withdrawn from use in contraceptives, and attempts have been made to correlate the risk of VTE with different progestagen generations. The status of the safest progestagene has been assigned, not without controversy, to levonorgestrel. The ambiguity of study results, which is even found in prospective studies, is attributable to two factors. One of them is the increase in the incidence of diagnosis of VTE from 2.8 per 10,000 women in 2001 to 4.1 in 2009 which was reported for example in the Danish population of women of reproductive age who do not use hormonal contraceptives and are pregnant. The results of the study seem to be related both to improved diagnostics and to the increase in average BMI observed in the study population. The other factor refers to methodological errors in epidemiological studies, imprecise diagnosis, failure to take into account risk factors and failure to assess the influence of duration of combined hormonal contraception (the risk of thrombotic complications is known to be the highest in the first year of therapy or, more precisely, during the first couple of months).

Classic risk factors for VTE, aside from age and obesity, include hereditary and acquired thrombophilias, immobility, cancer, diseases of the connective tissue, pregnancy and the postpartum period (Table I). Combined hormonal contraception represents an additional risk factor irrespective of the route of administration.

Tab. I. Risk factors for venous thromboembolism

\begin{tabular}{lc}
\hline Genetic & Acquired \\
\hline $\begin{array}{l}\text { Mutation of factor V Leiden } \\
(\leq 5 \% \text { of the Caucasian population) }\end{array}$ & Age \\
\hline $\begin{array}{l}\text { Mutation of the prothrombin gene } \\
\begin{array}{l}\text { p20210A (2\% of the Caucasian } \\
\text { population) }\end{array}\end{array}$ & $\begin{array}{c}\text { History of venous } \\
\text { thrombosis }\end{array}$ \\
\hline Protein C deficiency & \begin{tabular}{c} 
Overweight, obesity \\
\hline Protein S deficiency
\end{tabular} \\
\hline Antithrombin deficiency & \begin{tabular}{c} 
Immobility \\
\hline Dysfibrinogenemias
\end{tabular} \\
\hline & $\begin{array}{c}\text { Infection } \\
\text { Extensive varicose } \\
\text { veins }\end{array}$ \\
\cline { 2 - 2 } $\begin{array}{l}\text { Smoking } \\
\text { therapy }\end{array}$ \\
\cline { 2 - 2 } $\begin{array}{c}\text { Pregnancy and the } \\
\text { postpartum period }\end{array}$ \\
\cline { 2 - 2 } $\begin{array}{c}\text { Combined hormonal } \\
\text { contraception }\end{array}$ \\
\hline
\end{tabular}

The correlation, however, should not be automatically extrapolated to MHT which uses different estrogens, often also different progestagens and different doses.

\section{Menopausal hormone therapy and \\ the risk of venous thromboembolism}

Initial clinical controlled studies failed to demonstrate any associations between MHT and the incidence of VTE [5]. The pioneering study by Devor et al., which comprised a total of 121 women with VTE diagnosed in a university hospital, did not find any increase in VTE risk among patients receiving $\mathrm{MHT}(\mathrm{RR}=0.6[0.2-1.8])$ [6]. Nevertheless, it must be noted that members of the study population also had other VTE risk factors: immobility, postoperative period and cancer, which made it potentially more difficult to assess the impact of MHT alone. Similar problems were found in the doubleblind randomized study conducted by Nachtigall et al. The baseline risk of thromboembolic complications determined in the study population consisting of women treated in care centres, was $20 \%$ higher than the incidence observed in the general population [7].

The first randomized controlled study conducted in a healthy female population to assess various MHT regimens based on the administration of conjugated equine estrogens (CEE) either alone or in combination with different progestagens, acronymed as PEPI (Postmenopausal Estrogen/Progestin Interventions), unfortunately failed to resolve doubts because the study group was too small (825 women in total) and the follow-up period was short, covering just three years [8].

It was not until a series of retrospective studies carried out in a number of European countries, Canada and the USA, and especially prospective cohort studies (Nurses' Health Study [9], Oxford Family Planning Association [10], Longitudinal Investigation of Thromboembolism Etiology [11] and lowa Women's Health Study [12]) that the doubts were cleared and MHT was demonstrated to have an adverse effect on the risk of venous thromboembolic complications (Table II). In the meantime, a significant contribution came from HERS (Heart and Estrogen/Progestin Replacement Study [13]), i.e. an unsuccessful attempt to apply combined MHT in secondary prevention of ischemic heart disease, and WHI, which unequivocally demonstrated an increase in risk in both groups receiving hormone therapy (CEE + medroxyprogesterone acetate [MPA] and CEE alone). The risk was found to be additionally correlated with the women's age.

\section{Effects of estrogen type}

There are only a few individual studies comparing the effect of different estrogens employed in $\mathrm{MHT}$, al- 
Tab. II. Risk of venous thromboembolism in women receiving menopausal hormone therapy based on selected prospective studies

\begin{tabular}{lcc}
\hline Study & Publication year & RR (95\% Cl) \\
\hline Nurses' Health Study (NHS) & 1996 & $2.1(1.2-3.8)$ \\
\hline Oxford Family Planning Association Study (OFPAS) & 1996 & $3.5(1.8-7.0)$ \\
\hline Longitudinal Investigation of Thromboembolism Etiology (LITE) & 2010 & $1.6(1.06-2.36)$ \\
\hline lowa Women's Health Study (IWHS) & 2010 & $1.62(1.22-2.14)$ \\
\hline Randomized placebo-controlled studies & 2002 & $2.9(1.5-5.6)$ \\
\hline \begin{tabular}{l} 
Heart and Estrogen/Progestin Replacement Study (HERS) \\
\hline Women's Health Initiative (WHI) (CEE + MPA)
\end{tabular} & 2004 & $2.06(1.57-2.70)$ \\
\hline WHI (CEE) & 2004 & $1.33(0.86-2.08)$ \\
\hline CEE - conjugated equine estrogens, MPA - medroxyprogesterone acetate & &
\end{tabular}

though the majority of cited US studies investigated $\mathrm{CEE}$, and in Europe the dominant estrogen is micronized $17 \beta$-estradiol.

A clinical controlled study of perimenopausal and postmenopaual women aged 30-89 years encompassed a total of 586 cases of VTE and 2,268 women in the control group. An increased risk of venous thrombotic complications was only found in women using CEE (OR = 1.65 [1.24-2.19]). No risk increase, however, was identified in women receiving esterified estrogens (EE) $(\mathrm{OR}=0.92$ [0.69-1.22]) [14]. Nevertheless, there are no studies comparing the pharmacokinetics of both estrogen types. Conjugated equine estrogens are a natural extract obtained from the urine of pregnant mares, containing 10 different biologically active estrogens, not all of which have been fully characterized. The dominant estrogens, however, are estrone sulfate (53\%) and equilin sulfate (25\%). Esterified estrogens are also composed mainly of estrone sulfate (80\%) and equilin sulfate (11\%).

In a similar clinical controlled study, with a follow-up period of seven years, conducted in a cohort of women using oral MHT, the risk of VTE among women taking CEE was twice as high $(\mathrm{OR}=2.08$ [1.02-4.27]) as among women receiving estradiol [15]. Women taking CEE were found to have a statistically significantly higher $(p<0.001)$ activated protein $C$ resistance index.

Unfortunately, there are no randomized controlled comparative studies that would allow the formulation of unambiguous conclusions.

\section{Estrogen administration route}

For many years, studies did not make a distinction not only between different types but also different routes of administration of estrogens, especially that the oral route was initially the dominant method of administration. It was not until the publication of results of the French study ESTHER (Estrogen and THromboEmbolism
Risk) in 2003 that attention was first drawn to the significant difference resulting from the transdermal route of estradiol administration and its safety, with the implication that it did not increase the risk of VTE [16]. The study enrolled 155 consecutive cases of VTE developing in postmenopausal women and 380 women for the control group. In the group of women who had never used MHT, oral estradiol therapy was associated with an increase in relative risk of thrombotic complications ( $R R=3.5$ [1.8-6.8]). Transdermal therapy, on the other hand, caused no increase in risk $(R R=0.9$ [0.5-1.6]). The year 2007 saw the publication of results of the extended ESTHER study enrolling 271 first-time cases of VTE and 610 women in the control group. The study again demonstrated an elevated risk of VTE for oral estrogen therapy $(\mathrm{OR}=4.2$ [1.5-11.6]), and no increase in risk for the transdermal administration of estradiol ( $\mathrm{OR}=0.9$ [0.4-2.3]) [17].

Transdermal estradiol therapy appears to have no or negligible effect on the hemostasis system. However, oral estrogen therapy and the liver first-pass effect trigger the production of plasma clotting factors and an increase in the concentration of the proinflammatory factor C-reactive protein (CRP). A hypercoagulable state, measured by the concentration of prothrombin fragments $1+2$ [18], is observed. At the same time, a decrease in antithrombin concentration and an increase in the incidence of acquired resistance to activated protein C (APC) [19] are noted.

It would be worthwhile to conduct a randomized controlled study comparing both routes of estradiol administration to verify differences in activity described above.

\section{Effect of estrogen dose}

For oral estrogens, the risk of the first episode of VTE depends on the dose used. A metaanalysis of six observational studies showed that the risk for low-dose estrogen was OR = 1.57 (1.48-1.68), and for high-dose estrogen $-\mathrm{OR}=1.91(1.70-2.16)$, with $p=0.004$. How- 
ever, no dose dependency was seen for the transdermal route of estrogen administration.

\section{Comparison of thrombotic risk associated with oral estrogen and combined estrogen-progestagen therapies}

In the WHI study, combined therapy (CEE $0.625 \mathrm{mg}$ + MPA $2.5 \mathrm{mg}$ ) caused a significant increase in the risk of venous thromboembolic complications - 2.06 (1.572.70), whereas the estrogen arm (CEE $0.625 \mathrm{mg}$ ) did not exhibit a similar degree of significance, only a growth trend $(H R=1.33$ [0.86-2.08]) [20, 21]. Similar results were recorded in a prospective clinical controlled study by Douketis et al. - a significant increase in relative risk $(R R=2.7$ [1.4-5.1]) during estrogen-progestagen therapy and no increase in risk during therapy with estrogens alone ( $R R=1.2$ [0.6-2.6]) [22]. However, subsequent studies and a metaanalysis of clinical controlled and cohort studies based on them, point to a similar increase in risk triggered by oral MHT: both estrogenprogestagen $(H R=2.6[2.0-3.2])$ and estrogen alone $(H R=2.2$ [1.6-3.0] $)$ [23]. It is worthwhile to note that similarly to combined hormonal contraception the highest risk of VTE occurs in the first year of therapy.

A follow-up of patients who had discontinued MHT demonstrated that the risk of VTE returned to the level observed in the placebo group. The finding implies a transitory mechanism of hypercoagulability-associated disorders rather than an irreversible effect of the therapy on the venous system [17].

\section{Effect of progestagen type}

For a long time, no focus was given to the potential impact of progestagen on veins. Nevertheless, depend- ing on the strength of progestagen activity and binding to progesterone receptors in venous walls, there may be changes both in the structure and function of blood vessels potentially affecting the degree of thrombotic risk. The French ESTHER study cited above investigated not only the impact of estrogen administration route but also the effect of different progestagens, revealing significant differences between micronized progesterone and pregnanes, and norpregnanes (Table III).

The prospective cohort study E3N (Etude Epidémiologique de l'Education Nationale) of women born between 1925 and 1950, based on questionnaires filled at two-year intervals starting in 1990, found a total of 549 documented first-time episodes of VTE among 80,308 postmenopausal women [24]. The study again provided evidence that oral administration of estrogens is linked to an increased thrombotic risk ( $H R=1.7$ [1.1-2.8]), whereas the transdermal administration route carries no increased risk ( $\mathrm{HR}=1.1$ [0.8-1.8]). At the same time, however, the study assessed the effects induced by different progestagens. Neither micronized progeterone nor pregnanes (including dydrogesterone) had any impact on the risk of VTE: HR $=0.9(0.6-1.5)$ and $H R=1.3$ (0.9-2.0), respectively. Norpregnanes, which comprise nomegestrol acetate and promegestone, elevated the risk of venous thrombotic complications independently of estrogen $(H R=1.8$ [1.2-2.7]). Since the number of women treated with norethisterone was too small, it was impossible to analyze the effect of 19-norethisterone derivatives using statistical methods [17].

The risk of VTE seems markedly higher when combined MHT contains MPA. The Million Women Study found 2,200 cases of VTE among a total of 1,058,259 women. The relative risk of venous complications in comparison to women receiving no therapy was $\mathrm{RR}$ = 2.07 (1.86-2.31) for combined $M H T$, and $R R=1.42$

Tab. III. Effect of menopausal hormone therapy (MHT) on the risk of venous thromboembolism (VTE) depending on estrogen route of administration and progestagen type based on ESTHER [17] and E3N [24] studies

\begin{tabular}{|c|c|c|c|}
\hline \multirow[t]{3}{*}{ Therapy type } & \multicolumn{2}{|c|}{ ESTHER } & \multirow[t]{2}{*}{$\mathrm{E} 3 \mathrm{~N}$} \\
\hline & \multicolumn{2}{|r|}{ OR $(95 \% \mathrm{Cl})$} & \\
\hline & Nominal & Adjusted* & Adjusted \\
\hline No MHT & 1 & 1 & 1 \\
\hline History of MHT & - & - & $1.1(0.8-1.5)$ \\
\hline Oral estrogens & $3.6(1.5-8.8)$ & $4.2(1.5-11.6)$ & $1.7(1.1-2.8)$ \\
\hline Transdermal estrogens & $0.8(0.4-1.6)$ & $0.9(0.4-2.1)$ & $1.1(0.8-1.8)$ \\
\hline Micronized progesterone & $1.0(0.4-2.3)$ & $0.7(0.3-1.9)$ & $0.9(0.6-1.5)$ \\
\hline Pregnanes (e.g. dydrogesterone, chlormadinone acetate) & $1.0(0.4-2.3)$ & $0.9(0.4-2.3)$ & $1.3(0.9-2.0)$ \\
\hline Norpregnanes (nomegestrol acetate, promegestone) & $3.8(1.6-8.7)$ & $3.9(1.5-10.0)$ & $1.8(1.2-2.7)$ \\
\hline Norethisterone and derivatives & \multicolumn{2}{|c|}{ Not analyzed. Only 19 cases. } & $1.4(0.7-2.7)$ \\
\hline
\end{tabular}


(1.21-1.66) for oral estrogen therapy, with no observed increase in risk associated with transdermal administration of estrogens alone $-\mathrm{RR}=0.82$ (0.64-1.06). When different types of progestagen were analyzed separately, the risk related to MPA-containing therapy was significantly higher $(\mathrm{RR}=2.67$ [2.25-3.17]) than for other progestagens $(\mathrm{RR}=1.91$ [1.69-2.17]) [25].

\section{Additional risk factors for venous thromboembolism in menopausal hormone therapy}

Age is a known major risk factor for VTE. In the study by Danish authors cited above, the incidence of venous thromboembolic complications rose from 0.7 in women aged 15-19 years to 5.8 in women in the age group of 45-49 years [4]. This represents an 8.3 increase over the reproductive period in a woman's life. As shown in a detailed analysis of VTE cases in the WHI study, the age of menopause - but not the age of menarche - is implicated in the risk of thrombotic complications. A chart of the correlation resembles the shape of the letter " $U$ " because both women who go through menopause at a very early age (before 40 years old) and those with late menopause (after 56 years of age) are at an increased risk of these adverse events compared to women having their last menstruation at a regular age [26].

A similar clear correlation was seen in successive decades in the lives of women using combined MHT in the WHI study. The risk of VTE rose to 2.27 (1.19-4.33) among women aged 50-59 years, to 4.28 (2.38-7.22) among women aged 60-69 years and to 7.46 (4.3214.38) among women aged $70-79$ years in relation to the placebo group.

Obesity measured with BMI (body mass index) of over $30 \mathrm{~kg} / \mathrm{m}^{2}$ represents another indisputable risk factor for VTE. Importantly, in the WHI study the overweight status (BMI of $25-30 \mathrm{~kg} / \mathrm{m}^{2}$ ) was also associated with a consistent increase in the risk of venous thromboembolic complications during MHT, while correct body weight was only accompanied by a statistically insignificant increase in risk ( $H R=1.78$ [0.91-3.51]). Obese women taking oral estrogens are at an additionally increased risk of thromboembolic complications $(\mathrm{OR}=5.4$ [2.9-10.0]) relative to women of normal body weight receiving MHT whose VTE risk is equal to OR $=2.6$ (2.1-3.3). However, results obtained in the clinical controlled study conducted by Canonico et al. show that the transdermal route of administering estrogens does not entail a rise in the risk of thromboembolic complications in obese women.

A history of VTE elevates the risk of another episode of the disease even in a distant future, many years after the completion of anticoagulation treatment. A history of VTE represents a contraindication to oral MHT. Transdermal estrogen therapy seems a safe op- tion in these women. The MEVE (Menopause, Estrogen, Veins) study followed up, for eight years, a total of 1,023 postmenopausal women aged 45-70 years with a confirmed history of a VTE episode and with excluded genetic and acquired thrombophilia. A recurrence of the disease was observed in 77 women. The risk of VTE recurrence in women taking oral estrogens was found to rise in a statistically significant manner $(H R=6.4$ [1.5-27.3]). For transdermally administered estrogens, however, the risk level was the same as in women who did not use MHT, and equalled $H R=1.0(0.4-2.4)$ [27].

Thrombophilias. The presence of the mutation of factor $\mathrm{V}$ Leiden, the most common mutation in the Caucasian population, is a recognized risk factor for VTE. The effect of the mutation combined with oral estrogen therapy leads to a further increase in the level of risk which amounts to $\mathrm{OR}=8.0$ (5.4-11.9) compared to healthy women not receiving hormone therapy [28]. An analysis of 147 cases of VTE performed as part of the WHI study to assess the presence of the mutation of factor $\mathrm{V}$ Leiden, mutation of the prothrombin gene PT20210 and polymorphism C677T of methylenetetrahydrofolate reductase (MTHFR), showed a statistically significant correlation with the incidence of VTE only for the former mutation. In women without factor $\mathrm{V}$ Leiden (FVL) mutation the risk among those taking MHT was OR $=2.24$ (1.45-3.47), and among mutation carriers $-O R=6.69$ (3.09-14.49). The risk of VTE calculated for carriers of factor $\mathrm{V}$ Leiden mutation using MHT was $0.8 \%$ per year [18]. Attempts to assess the effect of other forms of hypercoagulability including a prothrombin gene mutation, presence of anticardiolipin antibodies and lupus anticoagulant, and hyperhomocysteinemia, have failed to resolve whether any of them are capable of adversely affecting the risk of VTE during MHT, probably due to a small number of diagnosed cases [29].

\section{Conclusions}

1. Venous thromboembolism is a very rare but very serious complication associated with $\mathrm{MHT}$.

2. Oral estrogens increase the risk of developing venous thrombotic complications. The degree of risk depends on the dose and possibly also the type of estrogen used.

3. In the light of results of observational studies, transdermal administration of estradiol does not carry an increased risk of VTE.

4. Oral combined estrogen-progestagen therapy seems to be linked to a slightly higher risk than estrogen monotherapy, however the degree of risk also depends on the type of progestagen used in the treatment.

5. Observational studies have not shown an increase in the risk of VTE to be linked to micronized pro- 
gesterone and dydrogesterone combined with transdermal estrogen.

6. Menopausal hormone therapy should preferably be selected on a case-by-case basis depending on indications, potential risks and women's preferences, taking into account additional risk factors for VTE.

\section{Disclosure}

\section{Author reports no conflicts of interest.}

\section{References}

1. Rekomendacje Polskiego Towarzystwa Menopauzy i Andropauzy na temat hormonalnej terapii menopauzy - stan wiedzy na grudzień 2013 roku. Prz Menopauzalny 2014; 13: 1-8.

2. Sturdee DW, Pines A, International Menopause Society Writing Group, et al. Updated IMS recommendations on postmenopausal hormone therapy and preventive strategies for midlife health. Climacteric 2011; 14: 302-320

3. Naess IA, Christiansen SC, Romundstad P, et al. Incidence and mortality of venous thrombosis: a population-based study. J Thromb Haemost 2007; 5: 692-699.

4. Tyler ET. Oral contraception and venous thrombosis. JAMA 1963; 185: 131-132.

5. Lidegaard $\varnothing$, Milsom I, Geirsson RT, et al. Hormonal contraception and venous thromboembolism. AOGS 2012; 91: 769-778.

6. Devor M, Barrett-Connor E, Renvall M, et al. Estrogen replacement therapy and the risk of venous thrombosis. Am J Med 1992; 92: 275-282.

7. Nachtigall LE, Nachtigall RH, Nachtigall RD, et al. Estrogen replacement therapy II: a prospective study in the relationship to carcinoma and cardiovascular and metabolic problems. Obstet Gynecol 1979; 54: 74-79.

8. The Writing Group for the PEPI Trial. Effects of estrogen or estrogen/ progestin regiments on heart disease risk factors in postmenopausal women. The Postmenopausal Estrogen/Progestin Interventions (PEPI) Trial. JAMA 1995; 273: 199-208.

9. Grodstein F, Stampfer MJ, Goldhaber SZ, et al. Prospective study of exogenous hormones and risk of pulmonary embolism in women. Lancet 1996; 348: 983-987.

10. Daly E, Vessey MP, Hawkins MM, et al. Risk of venous thromboembolism in users of hormone replacement therapy. Lancet 1996; 348: 977-980.

11. Ohira T, Folsom AR, Cushman M, et al. Reproductive history, hormone replacement, and incidence of venous thromboembolism: the Longitudinal Investigation of Thromboembolism Etiology. Br J Haematol 2010; 149: 606-612

12. Lutsey PI, Virnig BA, Durham SB, et al. Correlates and consequences of venous thromboembolism: the lowa Women's Health Study. Am J Public Health 2010; 100: 1506-1513.

13. Grady D, Wenger NK, Herrington D, et al. Postmenopausal hormone therapy increases risk for venous thromboembolism disease. The heart and estrogen/progestin replacement study. Ann Intern Med 2000; 132: 689-696.
14. Smith NL, Heckbert SR, Lemaitre RN, et al. Esterified estrogens and conjugated equine estrogens and the risk of venous thrombosis. JAMA 2004; 292: 1581-1587.

15. Smith NL, Blondon M, Wiggins KL, et al. Lower risk of cardiovascular events in postmenopausal women taking oral estradiol compared with oral conjugated equine estrogens. JAMA Intern Med 2014; 174: 25-34.

16. Scarabin PY, Oger E, Plu-Bureau G. Differential association of oral and transdermal oestrogen-replacement therapy with venous thromboembolism risk. Lancet 2003; 362: 428-432.

17. Canonico M, Oger E, Plu-Bureau G, et al. Hormone therapy and venous thromboembolism among postmenopausal women. Impact of the route of estrogen administration and progestagens: the ESTHER Study. Circulation 2007; 115: 840-845.

18. Post MS, Christella M, Thomassen LG, et al. Effect of oral and transdermal estrogen replacement therapy on hemostatic variables associated with venous thrombosis: a randomized placebo controlled study in postmenopausal women. Arterioscler Thromb Vasc Biol 2003; 23: 1116-1121.

19. Vehkavaara S, Silveira A, Hakala-Ala-Pietila T, et al. Effects of oral and transdermal estrogen replacement therapy on markers of coagulation, fibrynolysis, inflammation and serum lipids and lipoproteins in postmenopausal women. Thromb Haemost 2001; 85: 619-625.

20. Cushman M, Kuller LH, Prentice R, et al. Estrogen plus progestin and risk of venous thrombosis. JAMA 2004; 292: 1573-1580.

21. Anderson GI, Limacher M, Assaf AR, et al. Effects of conjugated equine estrogen in postmenopausal women with hysterectomy: the Women's Health Initiative randomized controlled trial. JAMA 2004; 291: 17011712.

22. Douketis JD, Julian JA, Kearson C, et al. Does the type of hormone replacement therapy influence the risk of deep vein thrombosis? A prospective case-control study. J Thromb Haemost 2005; 3: 943-948.

23. Canonico M, Plu-Bureau G, Lowe GD, et al. Hormone replacement therapy and risk of venous thromboembolism in postmenopausal women: systematic review and meta-analysis. BMJ Clin Pes 2008; 336: $1227-$ 1231.

24. Canonico M, Fournier A, Carcaillon L, et al. Postmenopausal hormone therapy and risk of idiopathic venous thromboembolism. Results from the E3N cohort study. Arterioscler Thromb Vasc Biol 2010; 30: 340-345.

25. Sweetland S, Beral V, Balkwill A, et al. The Million Women Study Collaborators. Venous thromboembolism risk in relation to use of different types of postmenopausal hormone therapy in a large prospective study. J Thromb Haemostat 2012; 10: 2277-2286.

26. Canonico M, Plu-Bureau G, O’Sullivan MJ, et al. Age at menopause, reproductive history, and venous thromboembolism risk among postmenopausal women. Menopause 2014; 21: 214-220.

27. Olié V, Plu-Bureau G, Conard J, et al. Hormone therapy and recurrence of venous thromboembolism among postmenopausal women. Menopause 2011; 18: 488-493.

28. Olié V, Canonico M, Scarabin PY. Postmenopausal hormone therapy and venous thromboembolism. Thromb Res 2011; 127 (Suppl. 3): S26-S29.

29. Douketis JD, Julian JA, Crowther MA, et al. The effect of prothrombotic blood abnormalities on risk of venous thrombosis in users of hormone replacement therapy. Clin Appl Thromb Hemost 2011; 17: 106-113. 